\title{
Health seeking behaviour of parents of burned children in Bangladesh is related to family socioeconomics
}

\author{
S.R. Mashreky ${ }^{\text {a,b,* }}$, A. Rahman ${ }^{\text {a }}$, S.M. Chowdhury ${ }^{\text {a }}$, L. Svanström ${ }^{\text {b }}$, S. Shafinaz ${ }^{\text {c }}$, T.F. Khan ${ }^{\text {d }}$, F. Rahman ${ }^{\text {a,b }}$ \\ ${ }^{a}$ Centre for Injury Prevention and Research Bangladesh (CIPRB), Dhaka, Bangladesh \\ ${ }^{\mathrm{b}}$ Department of Public Health Science, Karolinska Institutet, Sweden \\ ${ }^{\mathrm{c}}$ UNICEF, Bangladesh \\ ${ }^{\mathrm{d}}$ Centre for Medical Education, Bangladesh
}

\section{A R T I C L E I N F O}

Article history:

Accepted 18 May 2009

\section{Keywords:}

Child

Burn

Health seeking behaviour

Low-income countries

Bangladesh

\begin{abstract}
A B S T R A C T
Objective: The study was design to explore the health seeking behaviour of Bangladeshi parents for their children during burn injuries.

Methods: A population-based cross-sectional survey was conducted between January and December 2003 in Bangladesh. Nationally representative data were collected from 171,366 rural and urban households comprising of a total population of 819,429, including 351,651 children of $0-18$ years. Mothers or heads of households were interviewed with a structured questionnaire in obtaining the information.

Results: About sixty percent parents seek health care from unqualified service providers for their children during a childhood burn injury. Educated and the higher income groups parents choose qualified service provider at significantly higher rate compared to illiterate and poor. Higher proportion of parents of urban residence chooses qualified service provider compared to rural. No significant difference of health seeking behaviour of parent in choosing care provider was found in relation to sex of the children.

Conclusion: Education, economic condition and place of residence were found as the contributory factors in choosing service provider. Education to the parents can contribute in changes in health seeking behaviour which ultimately contribute in reducing morbidity and mortality from childhood burn injuries. Including parent's education a national burn prevention program needs to be developed to combat the devastating child injury, burn.
\end{abstract}

(c) 2009 Elsevier Ltd. All rights reserved.

\section{Introduction}

In terms of morbidity and long term disability burn is a huge public health issue throughout the world, especially in developing countries. ${ }^{18}$ Burn and its consequences are emerging as a major child health problems in our neighbouring countries like Nepal, India, Pakistan, Afghanistan, Sri Lanka and also in other developing countries. ${ }^{1,3,10,11,14,16,17,20}$ In Bangladesh childhood burn has already been established as a major child health problem and causing significant number of death disability and illnesses every year. ${ }^{14,15}$ Childhood burn is of special importance as children are much more vulnerable, have less perception about dangerous situations and have limited ability to react promptly and properly against it. ${ }^{2}$

Proper medical care can reduce consequences of any illness ${ }^{4,5,13,28}$ and ensuring proper care in childhood illness proper

\footnotetext{
* Corresponding author at: Centre for Injury Prevention and Research Bangladesh (CIPRB), Dhaka, Bangladesh. Fax: +880 28861499.

E-mail address: mashreky@ciprb.org (S.R. Mashreky).
}

health seeking behaviour of parents is important. Although childhood burn is a huge child health problem in Bangladesh health seeking behaviour of parents is yet to be studied and documented. This study was deigned to explore the health seeking behaviour of parent in Bangladesh after a childhood burn. The findings of this study will help to design a national strategy to attain better health seeking behaviour of parents to reduce consequences of childhood burn and this will ultimately contribute national burn prevention effort in Bangladesh.

\section{Methods}

Study design, area and population

This was a cross-sectional survey conducted during 2003 (January to December) in 12 randomly selected districts of Bangladesh and in Dhaka Metropolitan City. This encompassed a population of 819,429 which included 351,651 children less than 18 years of age.

Multi-stage cluster sampling was used to choose a total sample size of 171,366 households: 88,380 from rural areas, 45,183 from 
district towns (urban areas) and 37,803 households from Dhaka Metropolitan City. Bangladesh is divided in 6 divisions. Two districts were selected from each division by stratified random sampling. In each district, to represent the rural community, one upazila (sub-district) was randomly chosen and in each upazila two unions (administrative lowest units comprising of $\sim 20,000$ population) were selected randomly and each union was considered as a cluster. All households in the union were included in the survey. The district headquarters of the 12 selected districts and Dhaka Metropolitan City constituted the urban areas. In the urban areas, mohallas, the local political unit, served as clusters, and systematic sampling was done to achieve the required number of households.

\section{Case ascertainment}

Anyone under 18 years of age was considered as a child. A child was identified as a burn case when s/he took any treatment or could not perform normal activities at least three days due to the burn injury.

\section{Data collection and interview}

Forty-eight data collectors collected data from respondents using face to face to interviews. Along with the researchers, six fulltime supervisors were employed for supervision and monitoring the data collection process. A household member was defined as a person living in the same house including domestic helpers, long term guest, etc., sharing meals and information. Mothers were primarily preferred as respondents. However, if a mother was not available, the most knowledgeable member of the household was considered as the primary respondent. Where possible, the head of the household, and as many members of the household as possible were present to corroborate or add detail to the respondents' interview answers. Screening forms were used to identify any mortality or morbidity in the household.

The respondents were first asked whether any deaths had taken place in the household in the last 2 years in the national survey and 3 years in Dhaka metropolitan survey respectively, or any illness in the last 6 months. If any deaths or illnesses were identified, the interviewer proceeded with further clarification. Structured questionnaires were employed if burn injuries caused the death or illness which included questions about cause of burn, place of burn, and health seeking behaviour of the parents of the burn victim. Repeat visits were made to the household where respondents were unavailable on the first visit. In spite of repeated attempts, $2.7 \%$ households could not be interviewed. A total of $\mathbf{1 6 6 , 7 6 6}$ households participated in the study.

The service providers were categorized into two groups: qualified service providers and unqualified service providers. Qualified service providers included registered practicing doctors, private and government health centers and hospital. Unqualified service providers included govt. home visitors, non-government organization (NGO) field workers, who are involved only in health promotion activities at home and have no institutional degrees on health, homeopathic practitioners, herbal medicine practitioners, medicine shopkeepers, traditional healers/religious leaders and relative/friends.

Literacy: Person who attended school at least for 1 year was called literate and who never attended school was designated illiterate.

Health seeking behaviour of parents was observed in terms of choosing service providers for their children after a childhood burn.

\section{Statistical analysis}

Results were expressed as percentages according to type of service provider. 'Type of service provider' was considered as dependent variables. The literacy level of parents, monthly family income, birth order of the child, place of residence, total number of children and sex of the children were considered as independent variables or predictors of health seeking behaviour. Initially Chisquare test was conducted to see significant association between dependent and independent variables.

Both crude and adjusted model of logistic regression were carried out to identify the factors influencing care seeking behaviour with 'type of service provider'. A crude model shows how a single covariate influences the dependant variable. An adjusted model shows how two or more covariates influence the dependant variable after adjusting the effect of each other. Sex of the children had no significant association with 'type of service provider'. So it was excluded from the regression model.

Predictors of the care seeking behaviour were estimated by calculation of odds ratios (OR) and 95\% confidence intervals (CI).

\section{Result (Fig. 1)}

A total of 351,651 children were found among 819,429 population surveyed. Among them 1013 were found with burn injury. For management of burn injury about 60 percent of the parents took their children to unqualified service providers. About $41 \%$ of the parents took their children to medicine shopkeepers for treatment of burns. Five percent went to friends or relatives and another $5 \%$ to homeopath and traditional healers. Herbal medicine practitioners treated more than $5 \%$ of the burnt children. About $40 \%$ parents choose qualified service provider after a child burn. About $23 \%$ of the children were taken to government and private hospitals and $17 \%$ parents took their children to registered medical practitioners after a childhood burn.

\section{Place of residence (Table 1)}

Urban parents were more likely to choose qualified service providers for their children with burn injury than rural parents. It was observed that $63.2 \%$ of the urban parents brought their children to registered physicians or hospitals, where as in rural areas it was only $35.9 \%$ (OR 3.10; 95\% CI 2.17-4.43).

\section{Literacy level of parents}

Fifty-one percent of the literate fathers took their children to qualified service providers, where as it was only $27.5 \%$ among the

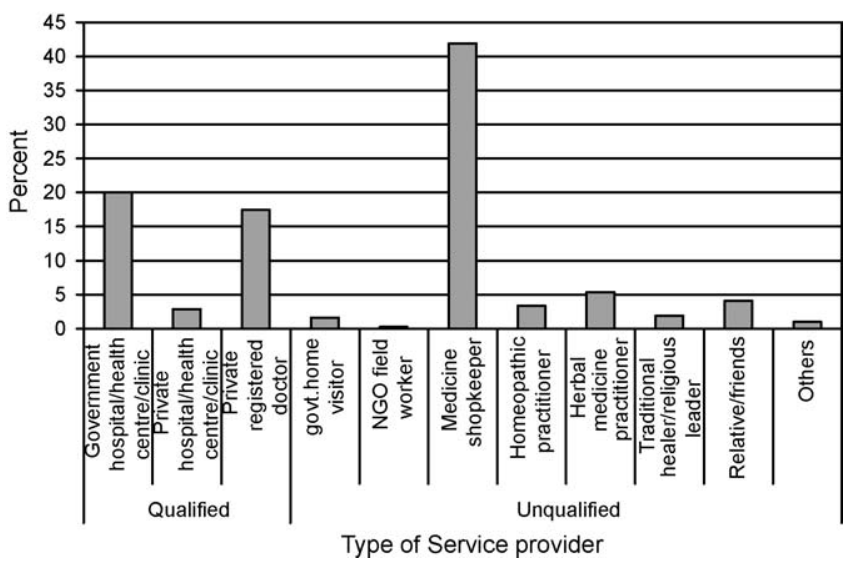

Fig. 1. Distribution of patients by health seeking pattern for burn $(N=974)$. 
Table 1

Factors influencing seeking service from qualified service provider.

\begin{tabular}{|c|c|c|c|c|c|c|c|}
\hline \multicolumn{4}{|c|}{ Taking treatment from qualified service provider } & \multicolumn{4}{|c|}{ Logistic regression } \\
\hline \multirow[t]{2}{*}{ Factors } & \multirow[t]{2}{*}{$n$} & \multirow[t]{2}{*}{ Frequency } & \multirow[t]{2}{*}{$(\%)$} & \multicolumn{2}{|c|}{ Crude } & \multicolumn{2}{|c|}{ Adjusted $^{\mathrm{a}}$} \\
\hline & & & & OR & $95 \% \mathrm{CI}$ & OR & $95 \% \mathrm{CI}$ \\
\hline Literate mother & 495 & 234 & $47.3 \%$ & 2.10 & $1.61-2.76$ & 1.26 & $0.90-1.75$ \\
\hline Illiterate mother & 438 & 131 & $29.9 \%$ & 1.00 & & & \\
\hline Literate father & 480 & 246 & $51.3 \%$ & 2.79 & $2.12-3.66$ & 1.90 & $1.36-2.64$ \\
\hline Illiterate father & 451 & 124 & $27.5 \%, 27.5 \%$ & 1.00 & & & \\
\hline 1 st order child & 303 & 135 & $44.6 \%$ & 1.51 & $1.11-2.04$ & 1.49 & $0.92-2.40$ \\
\hline 2nd order child & 231 & 97 & $42.0 \%$ & 1.36 & $0.98-1.89$ & 1.45 & $0.93-2.27$ \\
\hline 3rd order child & 413 & 143 & $34.6 \%$ & 1.00 & & & \\
\hline$\leq 2$ children in family & 392 & 175 & $44.6 \%$ & 1.43 & $1.09-1.86$ & .99 & $0.64-1.53$ \\
\hline$>2$ children in family & 555 & 200 & $36.0 \%$ & 1.00 & & & \\
\hline$>3000$ BDT monthly income & 442 & 215 & $48.6 \%$ & 1.88 & $1.45-2.45$ & 1.42 & $1.05-1.91$ \\
\hline$\leq 3000$ BDT monthly income & 528 & 177 & $33.5 \%$ & 1.00 & & & \\
\hline Urban residence & 155 & 98 & $63.2 \%$ & 3.10 & $2.17-4.43$ & 2.47 & $1.67-3.67$ \\
\hline Rural residence & 818 & 294 & $35.9 \%$ & 1.00 & & & \\
\hline
\end{tabular}

OR calculated by logistic regression.

a All of the independent variables mutually adjusted in adjusted logistic regression

illiterate (OR 2.79; 95\% CI 2.12-3.66). Like father, 47.3\% literate mothers took their children to qualified service providers ant it was $29.9 \%$ in case of illiterate mother (OR 2.10; 95\% CI 1.61-2.76). Association between literacy of parents and choosing service provider was found statistically significant.

\section{Monthly family income}

A significant association was found between monthly family income and health seeking behaviour of the parents. Higher income group parents chose qualified service providers for their children at a higher rate compared to poor (OR 1.88; 95\% CI 1.45-2.45). Among high-income group $48.6 \%$ parent choose qualified service provider and on the other hand it was only $33.5 \%$ among poor.

\section{Birth order of children}

Parents took their 1 st child to a qualified service provider at higher rates (OR 1.51; 95\% CI 1.11-2.04) compared to their following children. It was observed that 44.6, 42.0 and $34.6 \%$ children took treatment from qualified service providers where birth order of the children was 1st, 2nd and 3rd or above, respectively.

\section{Family size}

A higher proportion of children belonging to families with lower numbers of children were taken to the qualified service providers (OR 1.43; 95\% CI 1.09-1.86). More than 44\% parent choose qualified service provider for their children after a childhood burn who have 2 children or less on the other hand only 36\% parent took their children to qualified service provider who have more than 2 children.

\section{Gender}

Study findings show that parents took their female children with burn injury to qualified service providers at a slightly higher proportion than the male children (43.5 percent and $37.9 \%$, respectively). This difference between care seeking for male and female children was not significant.

The adjusted odds ratio revealed that parents' education and financial condition were the important contributory factors in choosing service provider for their children after a burn injury. Educated parents took their children to qualified health service providers at a higher rate compared to non-educated parents. Urban parents choose qualified service provider at a significantly higher rate compared to rural.

\section{Discussion}

In Bangladesh about 173,000 children get burnt and 3400 of them become permanently disabled every year. ${ }^{14,15}$ High incidence of this devastating injury and its consequences need to be prevented. Proper health seeking behaviour of parents could help in reducing burn consequences. About two-thirds of childhood burn victims were treated in Bangladesh by unqualified service providers because of parents' choice. Medicine shopkeepers were the first choice care providers for the treatment of childhood burn. Traditional healers, friends and relatives are also treating a significant proportion of burnt children because of their parents' choice. Preference of seeking health care from unqualified service providers was higher among poor, illiterate and rural people.

In many other developing countries analogous pattern of health seeking behaviour of parents has been observed during other illnesses of their children. ${ }^{7,8,23,24,27}$ After much search for literature specifically dealing with parents' health seeking behaviour in case of childhood burn one study of Ghana was found which revealed that $48 \%$ of the burned children were taken to a modern health facility. Economic condition, place of residence, severity and complication of burn were the factors in choosing modern healthcare in Ghana, however no association was found between mother's education and choosing health care. ${ }^{6}$ On the contrary mother's education was found as a significant factor in choosing and utilizing health service in many other studies ${ }^{13,22}$ including Bangladesh. Belief and understanding about health problems is an important factor in health seeking behaviour. ${ }^{12}$ Health belief plays an important role in determining whether a mother will seek traditional or biomedical (modern) health care for her children. Study findings reveal that mothers who hold modern beliefs are more likely to visit qualified service providers. ${ }^{7}$

Socioeconomic condition and maternal education were found as contributory factors in health seeking behaviour for children in Vietnam. ${ }^{26}$ People of poor financial condition were found reluctant to seek health care in China. ${ }^{29}$ Similar finding has been revealed in Nepal and in many other African countries. ${ }^{8,9,21,23,25}$ 
This study revealed that number of children in a family was an important factor in health seeking behaviour of parents for their children during a burn injury. Parents having fewer children took their children to a qualified service provider at a significantly higher proportion in comparison to the parents having more children in the family. Association was also found between birth order of the children and parent's health seeking behaviour. Early order children were taken to qualified service providers at a higher rate compared to following order children. This study had limitation to explore the reason behind it. Maybe because parents are always more concerned about their first issue. Maybe with successive issues they get more confident about handling the situation themselves. Maybe increasing poverty with increasing number of children causes inability to seek qualified health care.

A similar feature in health seeking behaviour was found in Africa in cases of malaria management. ${ }^{9}$

In this study relatively poor health seeking behaviour was observed among rural parents. Rural parents brought their children 3 times less often to a qualified service provider. Similar type of trends in health seeking behaviour of parents was also observed in other developing countries. ${ }^{8,22}$ In Brazil it was found that remote rural people were unwilling or delayed in going to modern service due to the absence of a modern transport system and/or the inability to pay the cost of treatment. ${ }^{22}$ Similar factors might be the reason for the rural people of Bangladesh to take service from unqualified service providers as these unqualified service providers are easily accessible and always available.

In Bangladesh unqualified service providers are providing health services to a huge number of patients with different kinds and levels of health problems. As both the literacy rate and financial condition of the people in this country are very low, people's perception about health service and service-seeking behaviour will not be similar to high-income countries.

Regarding choosing care provider Bangladeshi parents clearly value female children as much as male children, a thing that has not been observed in some other low-income countries. ${ }^{19,25}$ An important factor could be the cultural norm of this country of getting girls married off. This can be quite difficult and a costly process if the girl carries scars or disabilities due to burns. This in turn will make her a burden to her family. Another reason for such health seeking behaviour could also be the impact of government and non-government initiatives for gender equity in the society. Lot of work is going on for, female education, professionalism and women empowerment.

\section{Strength and limitation}

Findings about health seeking behaviour of the parents came from quantitative data only. Qualitative information could make the findings more comprehensive.

\section{Conclusion}

About two-third of the childhood burns were treated by unqualified service providers because of parents' option in choosing health care. Education, economic condition and place of residence were found as the contributory factors in choosing service provider. High prevalence of permanent disabilities is one of the major consequences of burn can be trimmed down by changing health seeking behaviour of the parents. Education program for the parents can contribute in changing in health seeking behaviour of them which ultimately can contribute in reducing morbidity and mortality from childhood burn injuries.

\section{Recommendation}

A national burn prevention program strategy needs to be developed to combat the devastating child injury, burn. Prevention strategy should include education program for parents at housed and community level both for prevention of burn and proper health seeking behaviour.

\section{Competing interests}

None declared.

\section{Ethical issues}

Ethical clearance was obtained from the Ethical committee of Institute of Child and Mother Health Dhaka. Participants were informed about the benefits and objectives of the study. Verbal consent was obtained from each head of household before proceeding with the interviews.

\section{Acknowledgement}

Financial support for the study was provided by UNICEF Bangladesh.

\section{References}

1. Ahuja RB, Bhattacharya S. Burns in the developing world and burn disasters. BMJ 2004;329:447-9.

2. Bang RL, Ebrahim MK, Sharma PN. Scalds among children in Kuwait. Eur J Epidemiol 1997;13:33-9.

3. Calder F. Four years of burn injuries in a Red Cross hospital in Afghanistan. Burns 2002;28:563-8.

4. D'SOUZA RM. Role of health-seeking behaviour in child mortality in the slums of Karachi Pakistan. J Biosoc Sci 2003;35:131-44.

5. de Silvaa MWA, Wijekoonb A, Hornik R, Martines J. Care seeking in Sri Lanka: one possible explanation for low childhood mortality. Soc Sci Med 2001;53: 1363-72.

6. Forjuoh SN, Guyer B, Strobino DM. Determinants of modern health care use by families after a childhood burn in Ghana. Injury Prevent 1995;1:31-4.

7. Goldman N, Heuveline P. Health-seeking behavior for child illness in Guatemala. Trop Med Int Health 2000;5:145-55.

8. Kloos H, Etea A, Degefa A, et al. Illness and health behaviour in Addis Ababa and rural central Ethiopia. Social Sci Med 1987;25:1003-19.

9. Kofoed EP, Rodrigues A, Có F, Hedegaard K, Rombo L, Aaby P. Which children come to the health centre for treatment of malaria? Acta Trop 2004;90:17-22.

10. Laloë V. Epidemiology and mortality of burns in a general hospital of Eastern Sri Lanka. Burns 2002;28:778-81.

11. Liu EH, Khatri B, Shakya YM, Richard BM. A 3-year prospective audit of burns patients treated at the Western Regional Hospital of Nepal. Burns 1998;24: 129-33.

12. Marcell AV, Halpern-Felsher BL. Adolescents' health beliefs are critical in their intention to seek physician care. Prev Med 2005;41:118-25.

13. Mbagaya GM, Odhiambo MO, Oniang'o RK. Mother's health seeking behaviour during child illness in a rural western Kenya community. Afr Health Sci 2005;5:322-7.

14. Mashreky SR, Rahman A, Chowdhury SM, et al. Epidemiology of childhood burn: yield of largest community based injury survey in Bangladesh. Burns 2008;34:856-62.

15. Mashreky SR, Rahman A, Chowdhury SM, et al. Consequences of childhood burn: findings from the largest community-based injury survey in Bangladesh. Burns 2008;34:912-8.

16. Mzezewa S, Jonsson K, Aberg M, Salemar L. A prospective study on the epidemiology of burns in patients admitted to the Harare burn units. Burns 1999;25:499-504.

17. Nega KE, Lindtjørn B. Epidemiology of burn injuries in Mekele Town Northern Ethiopia: a community based study. Ethiop J Health Dev 2002;16:1-7.

18. Panjeshahin MR, Lari AR, Talei AR, Shamsnia J, Alaghehbandan R. Epidemiology and mortality of burns in the South West of Iran. Burn 2001;27: 219-26.

19. Pokhrel S, Snow R, Dong H, Hidaya B, Flessa S, Sauerborn R. Gender role and child health care utilization in Nepal. Health Policy 2005;74:100-9.

20. Razzak JA, Luby SP, Laflamme L, Chotani H. Injuries among children in Karachi, Pakistan-what, where and how. Public Health 2004;118:114-20.

21. Schellenberg JA, Victora CG, Mushi A, et al. Inequities among the very poor: health care for children in rural southern Tanzania. Lancet 2003; 361:561-6. 
22. Souza A CTd, Peterson KE, Andrade FMO, Gardner J, Ascherio A. and Circumstances of post-neonatal death in Ceara Northeast Brazil: mother's health care-seeking behaviors during their infants' fatal illness.. Soc Sci Med 2000; 51:1675-93.

23. Sreeramareddy CT, Shankar RP, Sreekumaran BV, Subba SH, Joshi HS, Ramachandran U. Care seeking behaviour for childhood illness-a questionnaire survey in western Nepal. BMC Int Health Hum Rights 2006;6(7), http:// www.biomedcentral.com/1472-698X/6/7 accessed on 05.08.2007.

24. Suraratdecha C, Saithanu S, Tangcharoensathien V. Is universal coverage a solution for disparities in health care? Findings from three low-income province of Thailand. Health Policy 2005;73:272-84.

25. Taffa N, Chepngeno G. Determinants of health care seeking for childhood illness in Nairobi slums. Trop Med Int Health 2005;10:240-5.
26. Teerawichitchainan B, Phillips JF. Ethnic Differentials in Parental Health Seeking for Childhood Illness in Vietnam. Working Paper 2007; no. 3.The Population Council, Inc. New York, USA.

27. Uzochukwu BSC, Onwujekwe OE. Socio-economic differences and health seeking behaviour for the diagnosis and treatment of malaria: a case study of four local government areas operating the Bamako initiative programme in southeast Nigeria. Int J Equity Health 2004;3(6), http://www.equityhealthj.com/ content/3/1/6 accessed on 13.06.2007.

28. Varghese M, Mohan D, Occupational. Injuries among Agricultural Workers in Rural Haryana, India. J Occup Accid 1990;12:237-44.

29. Xu B, Fochsen G, Xiu Y, Thorson A, Kemp JR, Jiang QW. Perceptions and experiences of health care seeking and access to TB care-a qualitative study in rural Jiangsu Province, China. Health Policy 2004;69:105-49. 